\title{
ASSESSMENT OF THE SEVERITY OF THE CRISIS OF THE UKRAINIAN COMPANIES AND THE DEVELOPMENT OF MEASURES FOR ITS ELIMINATION
}

\author{
Vladimir NUSINOV ${ }^{1}$ \\ State Higher Educational Institution «Kryvyi Rih National University», Ukraine
}

\begin{abstract}
The functioning of the market system everywhere is accompanied by the crisis phenomena. It is impossible to imagine the development of a modern economy without economic UPS and downs, which disrupted the economic stability and the economic entities enter into a certain imbalance. Not exception-eating is the development of the crisis and companies of Ukraine. The origin and course of the crisis in Ukrainian companies requires a deep scientific study of modern economic theory and practice, as it can be considered a certain phenomenon, with significant features in comparison with other countries in crises companies. The manifestation of the crisis can be expressed in the decline in production, the deterioration of economic indicators, the financial insolvency of the company, have other symptoms that characterize its presence, as well as evaluate the various degrees of severity. Despite the fact that the Ukrainian company has led to a crisis, as it was heavy, and what the symptoms manifested, the main aim of the company in a state of crisis of uncertainty is the "survival" of the market and the continuation of further functioning. The issue of assessing the severity of the crisis and to identify measures to eliminate it in Ukrainian companies is extremely important and yet insufficiently developed. This is because, firstly, in economic science remains poorly understood the essence of the crisis, its species and assessment methodology taking into account the realities of the modern Ukrainian. Secondly, the emergence of the crisis in Ukraine - a frequent phenomenon, their course is quite difficult and time-consuming, but also has its own characteristics, depending on the formation of the Ukrainian political and economic systems, historically developed social and economic development of the country, the impact of external macroeconomic factors. These points need to be considered in the development of evidence-based, effective system of anti-crisis solutions for Ukrainian companies. The object of research is process of study of the crisis phenomena and the formation on its basis of anti-crisis measures in the companies. Subject of research - a set of theoretical, methodological and practical aspects of improving the assessment of the severity of the crisis of Ukrainian companies and the formulation of appropriate anti-crisis solutions. The methodological basis of this research is the dialectical method of cognition, systemic and historical approaches to the study of problematic issues, fundamental principles of the economic theory and the theory of crisis management. Applied the following research methods: logical generalization, systemic structural analysis, comparison, statistical, identifying cause-andeffect relationships, matrix, ranking, expert, etc. The purpose of the study is to improve estimates of the severity of the crisis, Ukrainian companies and develop appropriate anti-crisis solutions. In connection with this acute problem is to determine the characteristics and strategic respectively tactical crisis management and develop crisis toolstov in the system of corporate governance of Ukrainian companies. The obtained results determine the necessary methodological basis for improvement of the assessment of the severity of the crisis of Ukrainian companies and the formulation of appropriate anti-crisis solutions. Theoretical, methodical and applied results of research used in the process of crisis management of companies mining and metallurgical complex, shipbuilding and engineering industry of Ukraine.
\end{abstract}

Key words: crisis, causes of the crisis, consequences of the crisis, view of crisis, particularly the flow of the crisis, assessment of the severity of the crisis, crisis management

JEL Classification: $\mathrm{H} 12, \mathrm{O} 33$

Corresponding author:

${ }^{1}$ Department of Accounting, Taxation, Public Management and Administration, SIHE «Kryvyi Rih National University».

E-mail: vladimir.ya15@gmail.com 


\section{1. Введение}

Несмотря на то, что привело украинскую компанию к кризису, насколько он был тяжелым и какими симптомами проявился, основной целью компании в состоянии полной кризисной неопределённости явмяется «выживание» на рынке и продолжение Аальнейшего функционирования.

Проблематика оценки степени тяжести кризиса и определения мер его устранения в украинских компаниях исключительно важна и еще недостаточно разработана. Это обусловлено тем, что, во-первых, в экономической науке еще недостаточно изучена сущность кризиса, его видов и методологии оценки с учетом современных украинских реалий. Во-вторых, возникновение кризисов в Украине - частое явление, их протекание явцяется достаточно тяжелым и затяжным, а также имеет свои особенности, зависящие от формирования украинской экономической и политической систем, исторически сложившегося социально-экономического развития государства, влияния внешних макроэкономических факторов. Эти моменты необходимо учитывать при разработке научно-обоснованной, эффективной системы антикризисных решений Аля украинских компаний.

\section{2. Исследование сущности кризиса И еГО ВИАОВ}

В результате анализа митературных источников установмено, что концепция кризиса явмяется многоаспектной, так как используется в различных областях: меАицине, экономике, управлении, истории, психологии, политических науках, международных отношениях и так Аамее. Это объясняется существованием разных научных школ и задач исследования.

Считаем, что Амя применения эффективных метоАов антикризисного управления необходимо четко понимать сущность кризиса, его виАы, природу возникновения и возможные послеАствия.

Установлено, что на сегодня существует множество подходов к исслеАованию понятия «кризис», а именно: Аиалектический, классический, комплексный, нарушенного равновесия, положительный, отрицательный, процессный, развития, синергетический, сбалансированно-пропорциональный, системно-Аинамический, ситуационный, случайного характера, субъективно-объективный, правовой, факторного влияния, этимологический и др. ОпреАелено, что по классификационным признакам их можно сгруппировать в три блока: описательный; прескриптивный; правовой (Artiukh-Pasiuta, 2014; Kovalenko, Suhaniaka, \& Fuchedzhy, 2013; Pronoza, 2014; Tkachenko \& Kaliuzhna, 2013; Topij \& Kondrat, 2013; Vasylenko, 2013; Yankovskyj, Makohon \& Riabchyn, 2009).

Критический анамиз существующих научных поАходов к исслеАованию понятия «кризис» ПодтверАил, что перечень таких подходов с экономической точки зрения можно считать неполным. Установлена необходимость исследования кризиса на основе симбиоза прескриптивного и правового поАходов, что позвомяет учитывать экономические и правовые изменения в компании, а также ее корпоративные конфмикты. Считаем, что если указанные изменения в компании не произошии на Аанный момент времени, то тогда Аолжна оцениваться вероятность их наступиения. Таким образом, предложено в рамках патоэкономики (Pronoza, 2014) использовать контаминационный поАХоА К исслеАОванию кризиса, который наибольшей мерой раскрывает видение сущности кризиса и дает возможность максимально формализовать причинно-следственные связи его возникновения, протекания, послеАствий и миквиАации.

Обобщение результатов исследования сущности понятия «кризис» как зарубежными учеными, так и авторами постсоветского пространства позволияо установить, что на сегодня существует огромное количество Аефиниций кризиса, что само по себе уже есть признанием сложности и разночтения в понимании этой категории.

Подытожено, что митература относительно кризиса фрагментирована, так как авторы пишут о кризисах с различных точек зрения, не обобщая при этом идеи и концепции, разработанные специалистами Аругих областей. ВслеАствие указанного актуализируется необходимость уточнения Аанной Аефиниции.

Предлагаем опредемять кризис как явление, котоpoе характеризуется недопустимыми отрицательными отклонениями фактических результатов от желаемых с точки зрения его исслеАования в рамках контаминационного подхода.

Обобщение и сравнительный анализ результатов исследования сущности понимания кризиса авторами зарубежных источников и постсоветского пространства позволия определить, что зарубежными учеными при изучении кризиса рассматривается как сама компания, так и ее стейкхолдеры. В работах же авторов постсоветского пространства стейкхолдеры мибо вообще не рассматриваются, мибо рассматриваются очень усечено. Исходя из указанного, актуамизируется необходимость рассмотрения не только компании, а и ее стейкхолдеров при изучении кризиса на примере украинских компаний.

В настоящее время некоторые ученые постсоветского пространства при классификации кризисов используют понятия - виА и тип (Artiukh-Pasiuta, 2014; Kovalenko, Suhaniaka, \& Fuchedzhy, 2013; Pronoza, 2014; Tkachenko \& Kaliuzhna, 2013; Topij \& Kondrat, 2013; Vasylenko, 2013; Yankovskyj, Makohon \& Riabchyn, 2009). Это приводит к обособленному рассмотрению классификации видов кризиса и их типологии. Более того, некоторые ученые используют указанные понятия парамлельно и, например, 
при разработке собственной типизации кризиса в конечном итоге рассматривают его виды (ArtiukhPasiuta, 2014).

ПодАерживаем точку зрения, согласно которой термины «виА» и «тип» по отношению к кризису целесообразно разделить. Считаем необходимым Аифференцировать понятия «тип» и «виА» кризиса по критериям характеристики внутренних, и соответственно, внешних послеАствий.

Принимаем, что виА кризиса характеризует внутренние послеАствия, которые опреАеляют, с оАной стороны, комплексное изменение результата деятельности компании, а с Аругой - результаты собственника в части сохранения (потери) его корпоративных прав.

В соответствии с этим основными виАами кризиса выделяем следующие: финансовый, экономический, социальный, экологический, репутационный и корпоративный.

По нашему мнению преАложенная киассификация позволит разработать иерархию видов кризиса, показатемей оценки степени тяжести каждого из видов кризиса и, в конечном итоге, оценить степень тяжести кризиса компании на основе комплексного показатемя.

Все остальные кризисы преАлагаем определять как тип кризиса. Установлено, что тип кризиса, с оАной стороны, характеризуется Аополнительными эффектами у внешних стейкхолдеров, а с Аругой - явцяется описательным.

\section{3. Особенности протекания кризиса украинских компаний}

Особое значение приобретают исследования, связанные с изучением циклов кризиса, которые дают возможность определить момент времени возобновмения эффективной работы компании.

Проведены исслеАования развития украинской экономики. Выявцено, что возникновение, протекание и выход из кризиса Аля многих украинских компаний имеет свои особенности. Амя всех украинских компаний общей характерной особенностью явцяется оАновременное вмияние на их развитие мировых и отраслевых кризисов вместе с опреАеменными политическими проблемами различных масштабов.

Исследованы особенности, а также симптомы, факторы и причины кризисов украинских компаний в 1991-2015 гг. Выявлено, что за исслеАуемый периоА в Украине произошло четыре крупномасштабных кризиса, которые явмяются антропогенными, а также имеют размичную степень тяжести.

Установмено, что протекающие в Украине кризисы можно разАелить на Аве группы:

1. Кризисы, вызванные политическими явлениями (1991-1994 гг., 2014-2015 гг.).
2. Кризисы, которые протекают по классическому сценарию (1998-1999 гг., 2008-2009 гг.)

Подытожено, что наиболее тяжелым и затяжным кризисом Аля украинских компаний, не имеющим ранее аналогов, явился кризис 2014-2015 гг. Выявмено, что основной его причиной стац конфмикт экономических, политических и гражАанских интересов как внутри страны, так и за ее пределами. А фактором - отсутствие четкой позиции руководства страны относительно «западного» или «восточного» выбора, Аиктатура и коррупция власти, а также глубочайший политический кризис страны, в результате которого Украина потеряла АР Крым, вслеАствие его аннексии, вошиа в военный конфликт на востоке Украины (в Аонецкой и Ауганской областях), а также понесла существенный экономический урон. Кроме того, на существующую нестабильную экономическую ситуацию наслоилась неблагоприятная конъюнктура на внешних рынках и торговые ограничения со стороны Российской Федерации.

Выявлено, что наслоение глубокого политического кризиса, привеАшего к потере территориальной целостности Украины, на не окрепшую от предыдущего кризиса экономику страны, вызвало цепную реакцию Аисбаланса всех макроэкономических показателей и привело к затяжному упаАку.

Определено, что в период текущего кризиса особое значение имеют взаимоотношения внутренних стейкхолдеров (собственников, топ-менеАжеров и персонала компании). Особенность протекания текущего кризиса в украинских компаний состоит в слеАующем: при наличии политической нестабильности, всевозможных выступлений против вАасти или отАельных групп политиков наблюдается отсутствие забастовок, направленных против руководства и собственников компании, сплочение работников вокруг мажоритарных собственников Аля удовлетворения общих интересов - сохранения компании в период кризиса. В связи с эти обосновано, что с точки зрения компании кризис Аолжен оцениваться исходя из интересов мажоритарного собственника, который принимает конечное решение относительно функционирования компании, явцяется гарантом социацьной защищенности персонаца и сохранения рабочих мест.

Констатировано, что кризисы в Украине характеризуются высокой степенью убыточности компаний, большим количеством обанкротившихся и миквиАированных преАприятий. По нашему мнению миквиАация не обязательно Аолжна быть связана с изменением юриАического статуса компании. Считаем, что отдельно необходимо рассматривать юридическую, регламентированную Хозяйственным Кодексом Украины, и экономическую миквиАации компании. Последнюю целесообразно разделять на принуАительную миквиАацию бизнеса; снижение результатов работы компании, его собственных активов Ао нуля. ОтАельно слеАует рассматривать квази-ликвиАацию 
компании, как изменение ее юридического статуса вследствие факта ее миквиАации, после которой интересы главных внутренних стейкхолдеров компании сохранены и не пострадали.

\section{4. Оценка степени тяжести кризиса украинских компаний}

Проведенный обзор научной митературы позвомик установить отсутствие еАиного подхода к оценке кризиса компании, так как при этом применяются размичные градации: этапы, степени, фазы, масштабы, глубина кризиса и т. А (Kovalenko, Suhaniaka, \& Fuchedzhy, 2013; Pronoza, 2014; Tkachenko \& Kaliuzhna, 2013; Vasylenko, 2013; Yankovskyj, Makohon \& Riabchyn, 2009). Раздемяем мнение тех авторов, которые оценивают степень тяжести кризиса компании. ОАнако при этом авторами таких работ не определяется сущность Аанного понятия. ПреАлагаем поА «степенью тяжести кризиса» понимать сравнительную величину, установленную на основании совокупности симптомов, причин и факторов кризиса, и характеризующую состояние компании на оцениваемый момент времени отсутствием мибо наличием кризиса, интенсивностью его протекания и возможными послеАствиями.

Считаем целесообразным применение пятиуровневой градации степени тяжести кризиса, а именно: отсутствие кризиса, мегкая, среАняя, тяжелая, критическая степени тяжести кризиса. Полагаем, что преАложенная градация интуитивно понятна всем группам стейкхолдеров, вовлеченным в процесс антикризисного менеАжмента и наиболее полно характеризует состояние компании с точки зрения возможных антикризисных мероприятий. По нашему мнению критическая степень тяжести кризиса Аолжна Аиагностироваться в случае банкротства компании с ее послеАующей миквиАацией, потери бизнеса мажоритарными собственниками, насимьственной остановки бизнеса.

Считаем целесообразным применение трехуровневой иерархической структуры видов кризиса компании. При этом на низшем уровне иерархии располагаются такие виды кризиса как финансовый, экономический, социальный и экологический. На слеАующем уровне Аанные виды интегрируются в финансово-экономический и социально-экологический. На первом уровне иерархии финансово-экономический и социально-экологический формируют кризис результатов Аеятельности. На этом же уровне иерархии расположен и корпоративный кризис, который явцяется автономным от Аругих виАов кризиса.

ПреАложено степень тяжести видов кризиса низшего уровня иерархии определять по ряду показатемей, а высших уровней иерархии - путем последовательной интеграции с превалированием интересов мажоритарных собственников.
Кроме того, при опредемении степени тяжести кризиса высшего уровня иерархии считаем целесообразным интегрировать степени тяжести кризиса по кажАой его составцяющей, основываясь на законах эмементарной экономической могики с помощью применения матриц парного сравнения. При этом матрицу сравнения степеней тяжести кризиса преАможено формировать путем соединения Авух показателей оценки кризиса нижнего уровня иерархии, что позволяет ранжировать сравниваемые объекты в Авухмерном пространстве. Использование трех и более параметров не исключается, но значительно усложняет процесс оценки.

Рекомендовано степень тяжести финансового, экономического, социального, экологического кризиса определять путем сопоставления текущих значений оценочных показателей с их базовыми значениями. В качестве базовых необходимо использовать значения Аокризисного периода.

По нашему мнению показатели, характеризующие интересы мажоритарных собственников, явцяются основополагающими Аля оценки степени тяжести экономического и финансового кризиса. Так, по финансовому кризису это вероятность банкротства; по экономическому - стоимость компании, величина собственного капитала и результирующего Аенежного потока.

С целью прогнозирования банкротства украинских компаний разработана экономико-математическая четырехфакторная модель. Преимуществом Аанной модели, в сравнении с традиционными, является то, что она позволяет определить как вероятность вхожАения в процеАуру банкротства, так и вероятность АиквиАации компании.

Считаем, что на базе выбранной стратегии и с учетом степени тяжести кризиса компании должен формироваться соответствующий набор тактических мероприятий, опредемяемых с учетом ограничения на максимацьно возможный период времени их выполнения.

\section{5. Антикризисное управцение компанией}

В результате проведенного исследования опреАелены максимальные периоды времени, в течение которого возможно провоАить антикризисные мероприятия. Рассмотрено Аве ситуации: когАа компания уже вошла в процеАуру банкротства и когАа компания еще не вошиа в нее, но имеется вероятность такого вхожАения. Аیя кажАой ситуации преАложен алгоритм опреАеления данного периода времени.

Установлено, что состояние исследуемых компаний характеризуется критической степенью кризиса и максимально возможная величина времени, в течение которого может осуществцяться антикризисное управление, составмяет не более, чем 3 месяца. 
Считаем, что управление компанией в кризисе Аолжно основываться на выборе антикризисной стратегии компании с учетом преАпосылок цикличности экономической Аинамики, выраженной эффектом жизненного цикла, и бизнес-циклов рынка/ отрасли. Указанное позволяет обосновать наиболее эффективную стратегию компании, использующую потенциал развития рынка, и сформировать на ее основе целесообразный набор альтернатив, который включает следующие варианты: миквидация компании, выживание с консервацией бизнеса, выживание без консервации, рост.

С целью предотвращения негативных действий со стороны кредиторов целесообразно создать из них экспертный комитет при собрании акционеров, и преАоставить ему наряду с мажоритарными акционерами полномочия «негатив-контроля» по наиболее значимым операциям хозяйственной деятельности компании.

Рассмотрены Ава варианта продажи части доли уставного фонда кредиторов, а именно: когАа рыночная стоимость больше стоимости требований, которые должны быть выкуплены акционерами в обмен на акции (Аоли в корпоративном фонде) предлагаемые кредиторам, и наоборот. А^я кажАого из этих вариантов предложены условия перехода соответствующей векичины обязательств к Аействующим акционерам.

С учетом функций экспертного комитета разработана матрица разделения полномочий межАу ним, акционерами, наблюдательным советом и менеджментом компании. Использованы следующие типы управменческих решений: утвержАение решений в рамках «негатив-контромя», их принятие и согласование.

Предлагаем все значимые события в деятельности компании утверждать мажоритарным акционерам и экспертному комитету.

Разработаны модели оценки целесообразности решений, принимаемых аффилированными кредиторами в процессе банкротства компании относительно ее миквидации. Рассмотрен вариант, когАа при выработке критериев принятия решений учитываются только экономические мотивы и, соответственно, вариант, когАа им априори необходимо принять решение о покупке целостного имущественного компиекса путем приобретения Аолгов кредиторов с сохранением компании или путем выкупа активов на открытых торгах при ее миквиАации.

Предложена методика распределения ресурсов межАу различными объектами инвестирования, направмяемых инвестором на выкуп требований интересующих их компаний в процессе банкротства последних.

В качестве целевой функции преАложено установить максимум величины Z по модели Г. Спрингейта, которая взвешена по стоимости компании, так как при банкротстве крупных компаний потери существенно выше, чем при банкротстве малых. Разработан амгоритм оптимизации при наличии ограничения по величине инвестиционных ресурсов.
Аналогичным образом может решаться задача, когда установлено ограничение не по величине инвестиционных ресурсов, а по минимацьно допустимым критическим значениям показателя $\mathrm{Z}$ по кажАой компании - объекту инвестирования.

Апробация преАложенного методического поАхода относительно распределения инвестиционных ресурсов осуществлена на примере судостроительных компаний: ПАО «Черноморский суАостроительный завоА», ОАО «Херсонский суАостроительный завоА» и ПАО «Николаевский суАостроительный завод Океан».

Выявмено, что Аля Аостижения ПАО «Черно-

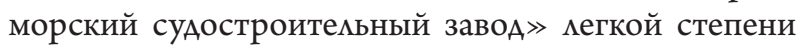
тяжести кризиса необходимо инвестировать в него 150 млн. грн, а ПАО «Херсонский судостроительный завоА» - 350 млн. грн.

\section{6. Выводы}

Аля более корректного исследования всего комплекса кризисных явлений рассмотрены характеристики уже прошеАших в Украине кризисов и опредемены особенности настоящего кризиса по причинам его возникновения, по послеАствиям, по масштабу проявлений, а также по роли стейкхолдеров в процессе его протекания.

Проблема отсутствия комплексного исследования оценки степени тяжести кризиса украинский компаний с учетом особенностей ведения хозяйственной деятельности в настоящем периоде, обусловила необходимость определения номенклатуры показателей степени тяжести кризиса, методики их оценки, а также агрегирования. Аля проведения последнего разработана иерархия показателей оценки степени тяжести кризиса, и на ее основе обеспечено их последовательное агрегирование с использованием матричного метода.

Украинские компании неоднородны, наряду с компаниями-гигантами существуют относительно крупные, среАние и малые компании. ВслеАствие их неоднородности Установлено, что оценку степени тяжести кризиса необходимо провоАить Аһя кажАой из этих групп компаний.

Конечной целью проводимых в работе исследований явмялось определение антикризисных мероприятий в украинских компаниях на современном этапе. В связи с этим острой проблемой явцяется опредемение особенностей стратегического и, соответственно, тактического антикризисного управления, а также разработка антикризисных инструментов в системе корпоративного управления украинских компаний. Основой послеАнего, по нашему мнению, являться определение условий вовлечения кредиторов в управление компаниями совместно с их собственниками. Аля этой цеми разработана матрица разделения полномочий межАу креАиторами, собственниками и менеАжментом компаний. 


\section{References}

Artiukh-Pasiuta, O. (2014), “Theoretical bases of typology of crises in the development and functioning of the enterprise", Zbirnyk naukovykh prats' Cherkas'koho derzhavnoho tekhnolohichnoho universytetu, vol. 35, pp. 81-87.

Baker, G. F. (2001). Race and reputation: Restoring image beyond the crisis in health. Handbook of Public Relations. Thousand Oaks: Sage Publishers, 513-520.

Bernstein, J. The 10 Steps of Crisis Communications. Bernstein Crisis Management. Retrieved from: http://www.bernsteincrisismanagement.com/the-10-steps-of-crisis-communications/

Coombs, W. T. (2011). Ongoing Crisis Communication: Planning, Managing, and Responding. UK: SAGE Publications, 231. Retrieved from: https://books.google.com.ua/ books?id=r6K0pRwbNn0C\&printsec $=$ frontcover $\& \mathrm{hl}=\mathrm{uk} \# \mathrm{v}=$ onepage \&q\& $\mathrm{f}=$ false

Fearn-Banks, K. (2007). Crisis Communications: A Casebook Approach. London, 402. doi: 10.4324/9780203936696

Kovalenko, V. V., Suhaniaka, M. V. and Fuchedzhy, V. I. (2013), Antykryzove finansove upravlinnia v systemi sub'iektiv ekonomichnoi diial'nosti: metody ta instrumenty otsiniuvannia Anticrisis financial management in the system of subjects of economic activities: methods and evaluation tools], Odesa, Ukraine.

Kozlowski, C. (2010). Crisis Management. Crisis Control Newsletter from RQA, Inc., UO110 (1). Retrieved from: https://www.rqa-inc.com/newsletters/Catlin_US_U0110.pdf

Lagadec, P. (1996). Un nouveau champ de responsabilité pour les dirigeants. Revue française de gestion, $100-109$. Retrieved from: http://www.patricklagadec.net/fr/pdf/revue_francaise_gestion_1996.pdf

Ömer, G. Definition and management of international crises. Center for strategic research Republic of Turkey Ministry of Foreign Affairs. Retrieved from: http://sam.gov.tr/wp-content/uploads/2012/02/OmerIsyar.pdf

Pronoza, P. V. (2014), Patolohycheskye kryzysnye protsessy v ekonomyke Ukrayny [Pathological the crisis processes in the Ukrainian economy], YNZhEK, Kharkiv, Ukraine.

Ross, D. How Crisis Communication Plans Work. How Stuff Works. Retrieved from: http://communication.howstuffworks.com/how-crisis-communication-plans-work.htm

Tkachenko, A. M. and Kaliuzhna, Yu. V. (2013), “Crisis: the nature, classification and causes”, Teoretychni i praktychni aspekty ekonomiky ta intelektual'noi vlasnosti : zbirnyk naukovykh prats', vol. 1, pp. $122-126$.

Topij, I. I. and Kondrat, Yu. (2013), "Theoretical approach to the interpretation of the concept "crisis" and the allocation of its inherent features”, Ekonomichnyj prostir, vol. 71, pp. 84-91.

Vasylenko, V.A. (2013), Ekonomyka znanyj y synerhetycheskye osnovy kreatyvnoho upravlenyia [The knowledge economy and the synergetic foundations of creative control], DYAJ-PY, Symferopol', Ukraine.

Yankovskyj, N. A., Makohon, Yu. V. and Riabchyn, A. N. (2009), Ynnovatsyonnye y klassycheskye teoryy katastrof y ekonomycheskykh kryzysov [Innovative and classical theories of catastrophes and economic crises] DonNU, Donetsk, Ukraine.

\section{Владимир НУСИНОВ}

\section{ОЦЕНКА СТЕПЕНИ ТЯЖЕСТИ КРИЗИСА УКРАИНСКИХ КОМПАНИЙ И РАЗРАБОТКА МЕРОПРИЯТИЙ ПО ЕГО УСТРАНЕНИЮ}

Аннотация. Функционирование рыночной системы повсеместно сопровождается кризисными явлениями. Невозможно себе представить развитие современной экономики без экономических подъемов и спадов, в результате которых нарушается экономическая стабильность, а субъекты хозяйствования вступают в определенныйдисбаланс. Неисключениемявляется развитиекризиса ив компанияхУкраины. Возникновение и протекание кризиса в украинских компаниях требует глубокого научного изучения современной экономической теорией и практикой, поскольку его можно считать определенным феноменом, имеющим существенные отличительные особенности в сравнении с кризисами компаний других стран. Проявление кризиса может выражаться в спаде производства, ухудшении экономических показателей, финансовой несостоятельности компании, иметь другие симптомы, характеризующие его наличие, а также оцениваться различной степенью тяжести. Несмотря на то, что привело украинскую компанию к кризису, насколько он был тяжелым и какими симптомами проявился, основной целью компании в состоянии полной кризисной неопределённости является «выживание» на рынке и продолжение дальнейшего функционирования. Проблематика оценки степени тяжести кризиса и определения мер его устранения в украинских компаниях исключительно важна и еще недостаточно разработана. Это обусловлено тем, что, во-первых, вэкономической науке еще недостаточно изучена сущность кризиса, его видов и методологии оценки с учетом современных украинских реалий. Во-вторых, возникновение кризисов в Украине - частое явление, их протекание является достаточно тяжелым и затяжным, а также имеет свои особенности, зависящие от формирования украинской экономической и политической систем, исторически сложившегося социально-экономического развития 
государства, влияния внешних макроэкономических факторов. Эти моменты необходимо учитывать при разработке научно-обоснованной, эффективной системы антикризисных решений для украинских компаний. Объектом исследования является процесс изучения кризисных явлений и формирование на его основе антикризисных мероприятий в украинских компаниях. Предмет исследования - совокупность теоретических, методических и практических аспектов усовершенствования оценки степени тяжести кризиса украинских компаний и раз-работки соответствующих антикризисных решений. Методологической основой данного исследования является диалектический метод познания, системный и исторический подходы к изучению проблемных вопросов, фундаментальные положения экономической теории и теории антикризисного управления. Применены следующие методы исследования: логического обобщения, системно-структурного анализа, сравнения, статистический, выявления причинно-следственных связей, матричный, рейтинговый, экспертный и др. Целью исследования является усовершенствование оценки степени тяжести кризиса украинских компаний и разработка соответствующих антикризисных решений. В связи с этим острой проблемой является определение особенностей стратегического и соответственно тактического антикризисного управления, а также разработка антикризисных инструментов в системе корпоративного управления украинских компаний. Полученные результаты исследования определяют необходимую методическую основу для усовершенствования оценки степени тяжести кризиса украинских компаний и разработки соответствующих антикризисных решений. Теоретические, методические и научноприкладные результаты исследования использованы в процессе антикризисного управления компаний горно-металлургического комплекса, судостроения и машиностроения Украины. 